\title{
Preservation of L. Rhamnosus with Calcium Alginate and It's of Survival Under Gastric Condition and in Yogurt
}

\section{Marwah Ali Oudah, K Rajyalakshmi, Syed Shabana and A Krishna Satya*}

Department of Biotechnology, Acharya Nagarjuna University, Nagarjuna Nagar, Guntur, Andhra Pradesh, India

*Corresponding Author: A Krishna Satya, Department of Biotechnology, Acharya Nagarjuna University, Nagarjuna Nagar, Guntur, Andhra Pradesh, India.

Received: November 06, 2019; Published: November 11, 2019

DOI: 10.31080/ASMI.2019.02.0433

\begin{abstract}
Potential strain isolated from mother milk sample, L. rhamnosus was selected from previous probiotic property studies is co -encapsulated with complementary Hi-Maize starch (a prebiotic) improved encapsulation of viable bacteria as compared to when the bacteria were encapsulated without starch. A preliminary study was carried out in order to monitor the effects of encapsulation on the survival of Lactobacillus rhamnosus in yogurt for storage and sensory evaluation over 8 week's storage. This study showed that the survival of encapsulated cultures of selected probiotic showed a decline in viable count of about 0.5 log over a period of 8 weeks while there was a decline of about 1 log in cultures which were incorporated as free cells in yoghurt. Addition of probiotic bacteria (free or encapsulated form) reduces acid development in yogurt during storage studies. Post acidification in yogurt with encapsulated probiotic bacteria was slower compared to yogurt with free probiotic bacteria.
\end{abstract}

Keywords: L. rhamnosus, Encapsulation, Survival Studies, Yogurt and Sensory Evaluation.

\section{Introduction}

Microencapsulation have been successfully used to enhance and improve the viability of dairy fermentation for the production of concentrated lactic acid producing bacteria and to increase the survival rate in dairy products and mayonnaise [1,2]. Encapsulation with calcium alginate beads has been significantly widely used for immobilization of probiotic bacteria such that it was ease of handling, non toxic and low cost [3]. This encapsulation procedure is the best method to preserve the bacteria from environmental factors such as low $\mathrm{pH}$ and high bile concentration [4,5], and also in case of anaerobic bacteria, bacteriophages and in chemical agents and in antimicrobial agents.

Encapsulation method has been implemented to enhance the survival and delivery of the probiotic culture. Several researches have shown successful microencapsulation and coating of bacte- ria using various materials and methods. Several model studies are available where alginates have been used for the microencapsulation of probiotic bacteria for fermentation purpose or for incorporation into products [6-10]. The main objective of the present research were to optimize the encapsulation conditions of the probiotic bacteria and to evaluate the survival of encapsulated culture under stimulated gastric conditions and in yogurt over a period of 8 weeks during the storage studies and sensory evaluation.

\section{Methodology}

Encapsulation

The promising probiotic isolate screened were further investigated for encapsulation by a slight modification method of [11] was used, bacterial strains were cultivated in appropriate broth for $24 \mathrm{~h}$ at $37^{\circ} \mathrm{C}$. After that the cells were harvested by centrifugation at $2500 \times \mathrm{g}$ for $10 \mathrm{~min}$ at $4^{\circ} \mathrm{C}$. The cells were washed twice be- 
fore re suspending them in $5 \mathrm{~mL}$ normal saline. It served as the inoculums of free cells to prepare microencapsulated cells and for the survival studies. Now bacterial suspension in a saline solution re-suspended in aqueous alginate solutions with different ratios $(1: 2,1: 4,1: 6,2: 2,2: 4,2: 6,3: 2,3: 4,3: 6$ likewise $)$ at different alginate concentrations $(1 \%, 2 \%, 3 \%$ and $4 \% \mathrm{w} / \mathrm{v}$ ) (Sigma, Sigma Aldrich,) to achieve $10^{8} \mathrm{CFUmL}^{-1}$ (final concentration) and to study the efficiency and viability of capsulated beads. Then, the mixture of alginate and cells were added drop wise using $5 \mathrm{ml}$ or $10 \mathrm{ml}$ syringe with a needle attached at the end into different $40 \mathrm{~mL}$ calcium chloride solutions containing $0.5 \%, 1 \%, 2 \%$ and $3 \% \mathrm{Ca} \mathrm{Cl}_{2}$ $(\mathrm{w} / \mathrm{v})$. This solution was constantly homogenized using a magnetic stirrer situated at the bottom of the vessel, in order to prevent the beads from sticking together. A dropping height of $7-10 \mathrm{~cm}$ was used to ensure that spherical droplets were formed. Capsules were maintained in the calcium chloride solution for $30 \mathrm{~min}$ and then transferred to a saline solution.

\section{Efficiency of bacterial encapsulation:}

To determine the viable count of entrapped bacteria under different alginate and calcium chloride concentrations according to the methods of [12]. One gram of beads was released from calcium alginate capsules by sequestering calcium ions with a $0.1 \mathrm{M}$ phosphate buffer solution (at $\mathrm{pH}-7$ ). Then serial dilution was performed in a saline solution fallowed by bacterial count determination by plating. Bacterial counts contained in alginate capsules were expressed as CFUcapsule ${ }^{-1}$.

The efficiency of encapsulation was expressed as a percentage calculated by dividing microcapsule bacterial contents by the bacterial concentration of equal volumes of alginate suspension.

Survival of encapsulated beads at different storage temperatures

The encapsulated beads were divided into two batches and maintained at 4 and $22^{\circ} \mathrm{C}$. The numbers of cultural probiotic cells were determined at different time intervals $(3,6,9,20$ and 30 days) by releasing bacterial contents and plating on appropriate media. A total of 10 capsules were analyzed each time and three independent experiments (i.e. three replications) were performed at each temperature.

Survival of free and encapsulated strains in $\mathrm{pH}$ and bile

Tolerance to $\mathrm{pH}$ and bile was evaluated for free and encapsulated L. rhamnosus strain. Freshly prepared microcapsules $(1 \mathrm{~g})$ or 1
$\mathrm{mL}(8 \log \mathrm{cfu} / \mathrm{mL})$ of free cell suspensions placed separately in test tubes containing $10 \mathrm{~mL}$ of appropriate medium adjusted to $\mathrm{pH} 2.0$ and 3.0 were incubated at 37 _C for $24 \mathrm{~h}$. The cells were harvested, washed and immediately used for enumeration of viable cells at 0 $\mathrm{h}$ and $24 \mathrm{~h}$ by plating in appropriate media at 37 _C for $24 \mathrm{~h}$ after de-polymerization of the capsules in $10 \mathrm{~mL}$ phosphate buffer [13].

Tolerance of microencapsulated strains to various bile salt concentrations were carried out as similar to above said method. Briefly, $1 \mathrm{~g}$ of microcapsules or $1 \mathrm{~mL}$ of free cell suspension was transferred in test tubes containing $10 \mathrm{~mL}$ of appropriate medium with 0.3, 0.6 and $0.8 \mathrm{~g} / 100 \mathrm{~mL}$ bile salt (Merck, Darmstadt, Germany) concentration and incubated at 37 _C. The enumeration of viable cells was carried out at $0 \mathrm{~h}$ and $24 \mathrm{~h}$ (modified $[14,13]$.

Yogurt production

Three batches of set yoghurt including a control (without probiotic cultures) were made with probiotic bacterial cultures incorporated into the product in different states: free and encapsulated. The probiotic cultures were incorporated at the same time as the yoghurt cultures. Homogenized and pasteurized milk was heated to $451 \mathrm{C}$ and skim milk powder (SMP) was added with high-speed stirring, to make $180 \mathrm{~g} / \mathrm{l}$ total solids in yoghurt. Heating was continued to 80 - $851 \mathrm{C}$, and the mixture was held at this temperature for $20 \mathrm{~min}$. It was then cooled to $451 \mathrm{C}$ and the yoghurt starter culture was added. The probiotic cultures were added as free or encapsulated cultures. The yoghurt mix was distributed in $500 \mathrm{ml}$ plastic cups. Incubation was carried out at $42-431 \mathrm{C}$ until a pH of 4.5 was reached at which time the yoghurt was cooled in an ice water-bath and stored at $41 \mathrm{C}$ for 7 weeks. The ' 0 day' analysis were carried out after overnight cold storage of samples, and week 3, 5 and 7 analysis were carried out after 21, 35 and 49 days of storage, respectively.

\section{Determination of $\mathrm{pH}$}

The $\mathrm{pH}$ of yoghurt samples was determined using a Digital $\mathrm{pH}$ meter (Denver Instruments, USA). The pH meter was standardized using reference $\mathrm{pH} 4.0$ and $\mathrm{pH} 7.0$ buffer solutions. The yoghurt sample was stirred with a little distilled water before $\mathrm{pH}$ measurement.

\section{Sensory evaluation of yogurts}

Sensory evaluation of yogurts was carried out after 8 weeks of storage at 4 1C. A panel consisting of 6 members, (Members of As- 
sistant professors in Department of Food and Nutrition, Acharya Nagarjuna University) evaluated the yoghurt samples presented in coded cups in individual booths at room temperature. The process used a series of horizontal lines marked with degrees of intensity of yoghurt attributes such as appearance and colour, body and texture, acidity, flavour, after taste and overall liking. Scoring was performed on a hedonic scale of 1 - 15 with 1 being most desirable [15].

\section{Results and Discussion}

\section{Morphological identification of beads}

The size and shape of the probiotic encapsulated beads was identified using light microscopy. The size of the bead obtained in the present study is $0.5-1 \mathrm{~mm}$, and only small portion of the encapsulated bead is considered as the size range $<500 \mu \mathrm{m}$. Size difference is carried out using $1 \mathrm{~mm}, 500 \mu \mathrm{m}$ and $150 \mu \mathrm{m}$ sieve size. And the shape of the bead size I normally spherical sometimes due to height variance drop shape or elliptical shaped capsules was observed. The prebiotic Hi-Maize starch gives the much potential to the bead as in the shape, texture, viability and low $\mathrm{pH}$ and high bile concentrations.
Survival of strains in $\mathrm{pH}$ and bile and storage condition

The main criteria factor that effects the survival and growth of probiotic bacteria id low $\mathrm{pH}$ condition, and the results indicates that no significant decrease in viable count was identified in encapsulated bacteria. Survival rate is $75-80 \%$ under low $\mathrm{pH}$ condition with prebiotic Hi-Maize starch. And under bile concentration the survival rate was 75 - 85\% when compared to the free probiotic bacteria. (Table-1) The viability of bacteria on storage analysis was identified as much higher than the free probiotic bacterial cells. Viability of the encapsulated bacteria is compared with the previous results $[13,14,16-18]$. In these results they concluded that most advantage of encapsulation is the high survival rate under low $\mathrm{pH}$ and high Bile concentration. Another research reported that immobilization of bacterial cells Bifidobacterium bifidi and Lactobacillus acidophilus in calcium alginate was not much accuracy in protecting the beads under high concentration of bile ( 2 and 4\%) [19]. Prebiotic used in the present study aids the increase of survival rate under $\mathrm{pH}$ and bile conditions. These end products of fermentation exert significant positive health effects of the host [20]. On storage analysis under room and freeze condition the viability of the probiotic did not significantly alter the count of the bacterial cell (Table 2).

\begin{tabular}{|l|c|c|c|c|c|c|c|}
\hline Treatment & Initial mean & \multicolumn{3}{|c|}{ Acid concentration } & \multicolumn{3}{c|}{ Bile concentration (\%) } \\
\hline & & $\mathrm{pH} 2$ & $\mathrm{pH} 3$ & $\mathrm{pH} 6.5$ & 0.3 & 0.5 & 0.8 \\
\hline Free cells & $8.82 \pm 0.13$ & $7.23 \pm 0.35$ & $8.68 \pm 0.30$ & $8.81 \pm 0.16$ & $6.54 \pm 0.45$ & $8.23 \pm 0.10$ & $6.44 \pm 0.21$ \\
\hline Encapsulated & $9.71 \pm 0.18$ & $8.73 \pm 0.30$ & $8.67 \pm 0.34$ & $9.18 \pm 0.39$ & $9.16 \pm 0.35$ & $8.16 \pm 0.17$ & $9.27 \pm 0.52$ \\
\hline
\end{tabular}

Table 1: Survival of Encapsulated L. rhamnosus under gastric condition.

\begin{tabular}{|l|c|c|c|c|c|c|c|}
\hline Storage temperature & Moisture content & 0 days & 15 days & 30 days & 60 days & 90 days & Survival \% \\
\hline Beads at $4^{\circ} \mathrm{C}$ & $4.31 \pm 0.28$ & $8.37 \pm 0.32$ & $8.27 \pm 0.43$ & $7.11 \pm 0.88$ & $6.69 \pm 0.23$ & $6.53 \pm 0.17$ & $77 \%$ \\
\hline Beads at $25^{\circ} \mathrm{C}$ & $4.21 \pm 0.53$ & $9.15 \pm 0.18$ & $8.44 \pm 0.16$ & $7.32 \pm 0.18$ & $7.05 \pm 0.52$ & $6.89 \pm 0.24$ & $74 \%$ \\
\hline
\end{tabular}

Table 2: Storage analysis of Encapsulation and survival rate.

\section{pH changes during yoghurt storage}

The $\mathrm{pH}$ changes in the control and experimental yoghurts during storage at $4^{\circ} \mathrm{C}$ for a period of 8 weeks is shown in (Table 3). The control yoghurt with the traditional yoghurt starter cultures showed the lowest $\mathrm{pH}$. The final pH (at end of 8 week storage) of yoghurt with encapsulated probiotic bacteria was greater than the yoghurts inoculated with free probiotic bacteria. Probiotic bacteria are slow acid producers [21]. Sevaral research reports suggest that there was much difference in probiotic strains with respect to survival under acid condition. The acid production may increase on storage which was sensitivity to probiotic culture and this process is indicated as over acidification. A comparative studies between the capability of probiotic bacteria strain to survive over a short period of time ( 2 - 3 hours in stomach) and capability to survive over a long term period on storage in fermented such as yogurt is not recorded. The results suggest that on storage analysis of acidification of yogurt with encapsulated form was slower when compared to both control and free probiotic. 


\begin{tabular}{|l|c|c|c|}
\hline $\begin{array}{l}\text { Storage } \\
\text { (weeks) }\end{array}$ & Control & $\begin{array}{c}\text { Yogurt with free } \\
\text { L.rhamnosus }\end{array}$ & $\begin{array}{c}\text { Yogurt with Encap- } \\
\text { sulated form }\end{array}$ \\
\hline 1 & 4.59 & 4.62 & 4.68 \\
\hline 2 & 4.21 & 4.51 & 4.60 \\
\hline 3 & 4.09 & 4.40 & 4.52 \\
\hline 4 & 4.0 & 4.35 & 4.48 \\
\hline 5 & 3.98 & 4.31 & 4.45 \\
\hline 6 & 3.97 & 4.29 & 4.40 \\
\hline 7 & 3.95 & 4.25 & 4.37 \\
\hline 8 & 3.94 & 4.24 & 4.35 \\
\hline
\end{tabular}

Table 3: pH of yohurt on storage analysis.

Sensory evaluation

The average sensory scores of all panel lists are shown in table the appearance and color of the yogurt samples. Expected that addition of alginate capsules to yogurt mix could slightly color the yoghurts, but the panelist could not identify the differences in the appearance and color between yoghurts with encapsulated cultures from the other two treatments. The body and texture including smoothness of the yoghurt samples, however, showed significant differences between the yoghurts containing free probiotic bacteria and encapsulated bacteria. The yogurt gel is not a tight matrix but formed as a loose structure with fractal characteristics. This phenomenon was reported in yogurts made with encapsulated ropy and non ropy yoghurt cultures during storage [22]. The panel lists also could not differentiate the three types of yoghurts in flavor or after taste attributes. The mean overall liking scores were not significantly different between the three types of yoghurts (Table 4).

3. The results showed that there were no significant differences in

\begin{tabular}{|l|c|c|c|c|c|c|}
\hline Treatment & Appearance and color & Body and texture & Acidity & Flavor & After taste & Overall liking \\
\hline Control & 4.43 & 5.31 & 8.54 & 8.11 & 7.55 & 8.0 \\
\hline free probiotic yogurt & 4.78 & 5.65 & 9.11 & 9.32 & 8.12 & 7.81 \\
\hline Encapsulated yogurt & 5.11 & 9.05 & 8.32 & 7.19 & 7.22 & 7.78 \\
\hline
\end{tabular}

Table 4: Mean values of sensory evaluation of 6 panel members: (1-most desirable, 15-least desirable).

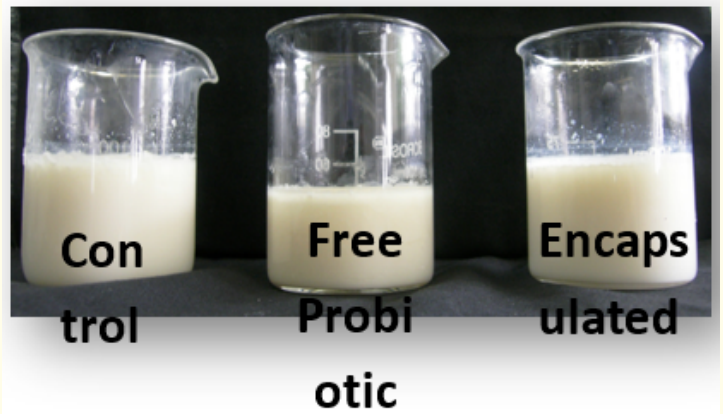

Figure 8: Illustration of control, free probiotic, and encapsulated yogurt.

\section{Conclusion}

The present research indicates that effect of probiotic Lactobacillus rhamnosus on encapsulation with calcium alginate beads with potential prebiotic Hi-maize starch give high survival rate under Gut condition (low pH and high bile concentration) and in- crease viability on storage conditions. On yogurt preparation with free and encapsulated form slows down the post- acidification on storage analysis when compared to the traditional yogurt (control). Usage of prebiotic Hi-maize starch helps to maintain the structure of yogurt texture. Sensory evaluation of the yogurt by panel member's results that addition of encapsulated probiotic did not much alter the appearance, color, acidity, flavor and taste of the yogurt. However slight variation in texture properties of yogurt and grittiness was observed in yogurt with encapsulated form. This research work suggests that the usage of Lactobacillus rhamnosus as potential probiotic by encapsulating with suitable prebiotic.

\section{Conflicts of Interest}

All authors have none to declare.

\section{Acknowledgments}

We would like to acknowledge and thankful Acharya Nagarjuna University, Department of Biotechnology for the use of their library facilities during the research findings. 


\section{Bibliography}

1. Lee., et al. "Survival of freeze-dried Lactobacillus bulgaricus KFRI 673 in chitosan-coated calcium alginate microparticles". Journal of Agricultural Food Chemistry 52. (2004): 7300-7305.

2. Krasaekoopt W., et al. "Survival Probiotics encapsulated in chitosan-coated alginate beads in yoghurt from UHT- and conventionally treated milk during storage". Food Science and Technology 39. (2006): 177-183.

3. Mortazavian A., et al. "Principles and methods of microencapsulation of probiotic microorganism". Iranian Journal of Biotechnology 5 (2007): 1-18.

4. Chou LS., et al. "Isolation and characterization of acid- and bile-tolerant isolates from strains of Lactobacillus acidophilus". Journal of Dairy Science 82 (1999): 23-31.

5. Succi M., et al. "Bile salt and acid tolerance of Lactobacillus rhamnosus strains isolated from Parmigiano Reggiano cheese". FEMS Microbiology Letters 244 (2005): 129-137.

6. Larisch BC., et al. "Microencapsulation of Lactococcus lactis subsp. Cremoris". Journal of Microencapsulation 11.2 (1994): 189-193.

7. Kim IK., et al. "Effects of rehydration and immobilisation in Ca-alginate on the survival of Lactobacillus casei and Bifidobacterium bifidum". Korean Journal of Dairy Science 18.3 (1996):193-198.

8. Khalil AH., et al. "Alginate encapsulated bifidobacteria survival in mayonnaise". Journal of Food Science 63.4 (1998): 702-705.

9. Jankowski T., et al. "Encapsulation of lactic acid bacteria with alginate / starch capsules”. Biotechnology Techniques 11.1 (1997): 31-34.

10. Kebary KMK., et al. "Improving viability of bifidobacterium and their effect on frozen ice milk". Egyptian Journal of Dairy Science 26 (1998): 319-337.

11. Sultana K., et al. "Encapsulation of probiotic bacteria with alginate-starch and evaluation of survival in simulated gastrointestinal conditions and in yoghurt". International Journal of Food Microbiology 62 (2000): 47-55.

12. Sheu TY., et al. "Micro-encapsulation of Lactobacilli in calcium alginate gels". Journal of Food Science 54.3 (1993): 557-561.
13. Mandal S., et al. "Effect of alginate concentrations on survival of microencapsulated Lactobacillus casei NCDC-298". International Dairy Journal 16 (2006): 1190-1195.

14. Lee KY., et al. "Survival of Bifidobacterium longum immobilized in calcium alginate beads in simulated gastric juices and bile salt solution". Applied Environmental and Microbiology 66. 2 (2000): 869-873.

15. Larmond E. "Laboratory methods for sensory evaluation of food”. Publication 1637/E. Ottawa: Canada Dept. Agric. Research Branch (1987).

16. Chandramouli V., et al. "An improved method of microencapsulation and its evaluation to protect Lactobacillus spp in simulated gastric conditions". Journal of Microbiological Methods 57 (2004): 27-35.

17. Iyer C., et al. "Effect of co-encapsulation of probiotics with prebiotics on increasing the viability of encapsulated bacteria under in vitro acidic and bile salt conditions and in yogurt". Journal of Food Science 70.1 (2005): 18-23.

18. Krasaekoopt W., et al. "Evaluation of encapsulation techniques of probiotics for yoghurt". International Dairy Journal 13 (2003): 3-13.

19. Trindade CSF, et al. "The effect of the immobilization of Lactobacillus acidophilus and Bifidobacterium lactis in alginate on their tolerance to gastrointestinal secretions". Milchwissenschaft 55 (2000): 496-499.

20. Kritchevsky D. "Epidemiology of fiber, resistant starch and colorectal cancer”. European Journal of Cancer Prevention 4.5 (1995): 345-352.

21. Marshall VM., et al. "Starter cultures employed in the manufacture of biofermented milks". International Dairy Journal 50 (1997): 35-39.

22. Hassan AN., et al. "Textural properties of yoghurt made with encapsulated non-ropy lactic cultures". Journal of Dairy Science 79 (1996): 2098-2103.

\section{Volume 2 Issue 12 December 2019 (C) All rights are reserved by A Krishna Satya., et al.}

